Changes to Environmental Policy: A Plea to Turn Passion into Action

Leland J. Jackson

University of Calgary
Scholarly and Research

Communication

VOLUME 5 / ISSUE 1 / 2014
I write this narrative from the perspective of an aquatic ecologist and professor at a Canadian university. I believe that many people who become practicing scientists follow, to varying degrees, the broad path that I did, and as a result, readers can substitute their particular interests and discipline for mine. The examples I use are drawn from personal experience, yet I hope the ideas can be applied to most, if not all, disciplines in the natural sciences and beyond (e.g., health). My history includes $\sim 20$ years of research and involvement in a number of government panels and review committees charged with evaluating science to measure ecosystem responses to a variety of environmental stressors. I have also served as an expert crown witness for a wetlands destruction lawsuit, allowing me to participate in the legal process. My job allows me to conduct research and interact with some high school and many undergraduate and graduate students. More and more, students arrive at my office door with an interest in environmental issues and a passion for doing something positive, but are not quite sure how to get started or what to do.

In overview, my opinion is that science often plays a regrettably small role in decisions that involve environmental policy creation and change and in the associated regulations designed to support that policy. That role can be strengthened if scientists focus on two elements: 1) generating relevant scientific knowledge, and 2) acting as agents to increase society's literacy for science-related issues.

CCSP Press

Scholarly and Research Communication

Volume 5, Issue 1, Article ID 0101132, 5 pages

Journal URL: www.src-online.ca

Received August 27, 2013, Accepted September 26, 2013, Published December, 19, 2013

Jackson, Leland J. (2013). Changes to Environmental Policy: A Plea to Turn Passion into Action. Scholarly and Research Communication, 5(1): 0101132, 5 pp.

(C) 2013 Leland J. Jackson. This Open Access article is distributed under the terms of the Creative Commons Attribution Non-Commercial License (http://creativecommons.org/licenses/by-nc$\mathrm{nd} / 2.5 / \mathrm{ca}$ ), which permits unrestricted non-commercial use, distribution, and reproduction in any medium, provided the original work is properly cited.
Leland Jackson is Professor of Community and Ecosystem Ecology in the Department of Biological Sciences at the University of Calgary, 2500 University Drive NW, Calgary, $\mathrm{AB}$, Canada, $\mathrm{T}_{2} \mathrm{~N}_{1} \mathrm{~N}_{4}$. Email: ljackson@ucalgary.ca . 


\section{Scholarly and Research}

\section{Communication}

VOLUME 5 / ISSUE 1 / 2014
In this article, I comment on how I think many scientists end up in science. My evidence is largely based on discussions with many undergraduate and graduate students who have shared their personal experiences with me. Second, as someone who conducts scientific research that can contribute to policy development, but does not create nor amend environmental policy, I comment on the role of science in the policy decision-making process. Finally, I make a plea for those in science, and in particular young scientists, to engage and involve themselves in efforts to become environmental advocates and increase society's scientific literacy. Meyer et al. (2010) provide some examples of ways to do this in a U.S. context, and Donald and Kovac (2013) provide a more prescriptive approach for educators - I recommend reading both. I believe there are numerous ways individuals can use their skills to be an environmental advocate.

\section{The attraction to science}

I think many pursue a career in science because they follow a passion to understand the natural world. For those in some field of the natural sciences, and particularly in my area of ecosystem ecology, often this is a path that follows childhood experiences with family or relatives who have provided some venue to fuel an innate curiosity regarding the world around us. Camping trips, fishing outings, summer vacation at the family cottage, hiking adventures, etc., often have provided opportunities to explore and question. Throughout our formal education, we take courses that provide not only conceptual foundations for our science, but an appreciation of the inter-connected, complex nature of biological life, whether our interests lie in molecules or ecosystems. We gravitate, naturally, to the areas that we find most intriguing, as this is where our interests and, likely not by chance, aptitudes lie.

Near the end of high school, I think, it is common to contemplate "what next," and one's education has provided a conceptual framework and enough practical examples to know there are some serious challenges regarding how our current quality of life can be sustained. In 2013, the global population surpassed 7 billion people, and it continues to grow; many natural resources exploited at today's harvest rates are effectively finite; and many economies are considered successful only if they continue to grow. However, sooner or later most realize that balancing today's level of prosperity and rate of economic growth with sustainable use of natural resources presents a daunting challenge. In some cases, these two objectives are, for all practical purposes, in conflict. For example, many marine fish populations have been exploited to the point where the top predators are no longer viable for fisheries (Pauley et al., 1998). Clearly, the notion that resources are effectively limitless or that we can simply engineer solutions that make more with less, indefinitely, is simply absurd. My personal passion concerns the availability of clean water. One in five people on the planet today ( $\sim 1.4$ billion people) does not have access to clean water, something the UN and most people consider a basic human right. For most Canadians, the abundance of natural resources has meant that, historically, not much thought has been given to this balancing act. Yet newspaper headlines over the last decade have provided much evidence that we need not only to start thinking about this, but to put into place public policy based on science that will protect the public's interest in our natural resources, the ecosystem services we derive from our environment, and the quality of life we too often take for granted. My discussions with high school, undergraduate and graduate students who are wondering "what next?" suggest that many young people fundamentally recognize the challenge 
society faces and want to "do something" about it. The question is, "how does someone relatively early in their career use their skills and knowledge derived from their formal education, and their passion to 'do something?'”

The intersection of recognizing a challenge and having a passion to make a positive change creates an opportunity. Recognizing a challenge allows one to focus one's effort. Large environmental issues will not be fixed in one step, and the really big issues require a sustained effort. Our passion to make a difference is an important motivator to deal with roadblocks and those who think the status quo cannot be changed. The opportunity to influence change arises from the creation of enough public awareness that a change in policy becomes an item of discussion, accompanied by members of the public voicing their opinions to elected officials. Our elected officials, in turn, have the power to create changes in policy and regulations to reflect society's desire for change. At the end of this process the ideal result is a balance that allows economic growth and sustainable resource use. Of course, if an opportunity to communicate directly with policymakers arises, all the better.

\section{Science and environmental policy}

Once a decision has been made that a policy change is required, that change in environmental policy should be informed by the best available science, economics, politics and perhaps additional factors, as illustrated in this simple equation:

\section{Policy change $=f$ (science, economics, politics, other factors $)$}

In an ideal world where governments attempt to balance economic growth and sustainability, the most recent science and economics would carry equivalent weight, with politics playing a minor role. In practice, it seems that underlying science often carries very little weight and decisions involve mostly economic and political considerations. Why might it be that science carries a small weight in the equation above? Possible reasons are that the appropriate science isn't available, in which case the weighting is zero, or close to zero if opinion is used in place of data. Recognition of the need for relevant science comes from early federal policy regarding wetlands, which around 1990 stated that scientific information should form the basis of wetland protection, mitigation and compensation decisions (MoE, 1991). However, as of today, almost 25 years later, the science to protect wetlands, mitigate damage, and determine appropriate compensation where wetlands are allowed to be destroyed, is lacking. Without the appropriate science, how can we expect a change in policy or regulations that is based on science?

In situations where science is available, the information or data can sometimes be in a form or place that is not accessible to policymakers, or the existing science might not be the specific information required by policymakers to address knowledge gaps. Thus, lack of data, inaccessibility, and lack of direct applicability combine with other reasons to limit the role of science in policy decisions. For example, those with the authority to make policy changes and set the regulations that will enforce that policy - our elected officials - are typically not scientists. As well, those who do the regulating (and work closely with those who create or change policy) are sometimes influenced by those who are regulated, a situation referred to as "bureaucratic slippage" (Freudenburg \& 
Scholarly and Research

Communication

VOLUME 5 / ISSUE 1 / 2014
Gramling, 1994). Regardless of how bureaucratic slippage comes about, it clearly represents an undesirable situation if, as they often are, the interests of the regulated group are at odds with the public's interests at large. For an example, negotiating limited expenditure on the treatment of waste products with regulated groups, rather than insisting on the public's interest in the minimization of waste or pollution, is a clear example of how bureaucratic slippage can weaken the public interest. If existing policy and regulations allow pollution, the public effectively subsidizes the regulated group's economic bottom line by reducing the group's expenses.

One positive example in which science paved the way for regulatory changes involves sentinel whole lake experiments, conducted at the Experimental Lakes Area (ELA) near Kenora, Ontario. These experiments identified phosphorus as the nutrient responsible for the greening of many freshwaters (Schindler, 1974). This research provided the scientific evidence that led to reductions in the phosphorus content allowed in detergents and municipal wastewater effluents. Society has benefited from these reductions by decreasing algal blooms in freshwaters as a result. The sentinel whole lake experiments are a prime example of 1) making policy decisions based on relevant scientific information and 2) increasing societal science-literacy so the general public can voice an informed and articulate opinion to elected officials. The public learned about the science at ELA and its implications when newspapers and television stations ran stories in the news.

We scientists play a role in addressing the science and knowledge gaps by conducting research, yet experience shows that the science by itself is often not sufficient to precipitate changes in policy. Science literacy, based on knowledge attained from high schools through to the highest levels of post-secondary education, can play a role in meeting the challenge of wise public policy. Why is it important that we have a scienceliterate society? One of the political motivations for decisions comes from the electoral cycle, typically four years. Ecosystem change may happen over decades. Clearly, these cycles are vastly different and require that decisions made today consider long-term consequences to ensure that the long-term benefits are not overshadowed by shortterm electoral interests. Policy decisions made and enacted may occur rapidly, but may have long lasting consequences or lifespans before modifications or changes occur. Therefore, society must be science literate to pressure politicians to make decisions that provide long term benefits even though such benefits might not be obvious or realized during the current electoral cycle. We can voice our opinions as scientists, and we can voice our opinions as voters. Voter turnout for federal elections has been dropping over the last decade compared to historic participation from (mean $+/-1$ standard deviation) $72.0+/-4.04 \%$ from $1867-1997$ to $61.9 \%+/-2.45 \%$ from $2000-2011$ (Elections Canada, 2013). If we want to see this change, we need to become involved in the solution and not simply sit by the wayside and complain. We need to vote, and we can play an advocacy role for environmental issues by educating our friends, neighbours, relatives, etc., about the need to vote and the science issues relevant to the election of the day.

\section{A plea to help increase society's science literacy}

Since elected officials make policy decisions the only way those decisions will reflect society's values is if those same elected officials hear the opinions and understand 
society's values. To articulate opinions regarding what society wants (e.g., new housing developments or existing wetlands that recharge aquifers with high quality, clean water) requires scientific literacy to understand relevant facts and effectively communicate opinions. Scientific literacy is aided by all scientists, regardless of experience, taking opportunities to inform roommates, friends, neighbours, and relatives. Sometimes, this involves sticking our neck out, because not all will share our opinions and may aggressively defend an alternative view, yet I think we need to view increasing society's scientific literacy as a necessary responsibility.

The benefit of an increase in society's science literacy is that the public can engage in informed debate with elected officials. The democratic process is the mechanism by which each of us voices our opinion regarding the governments' choice of policy and action or inaction on matters each of us deems essential to sustaining the public's natural resources. Thus, my plea is to look for opportunities to help create a broader science literacy. Talk to friends who haven't been exposed to science as you have. If you are a high school student, tell your parents and friends interesting things you have learned ("Did you know ..."). Look for groups at school or through volunteer opportunities. You can take the same approach if you are an undergraduate student. For example, I have been involved with local watershed groups that contain many motivated members who are eager to understand relevant science, yet don't have the means to pay for it. Early-career scientists have much to offer such groups. More experienced scientists can accept requests to talk about their research to school groups, serve as advisors to public groups, etc. View requests to contribute your knowledge and expertise as opportunities to advocate and educate. Identify a challenge and, above all, use your passion to make a positive difference!

\section{Acknowledgements}

The author wishes to thank Erick Elgin, Krista Larsen, Jarvis Singer, and Haley Tunna for providing very useful feedback on an earlier draft of this manuscript, as well as Rowland Lorimer for making a number of suggestions to improve clarity.

\section{References}

Donald, K.J., \& Kovac, J. (2013). The scientist's education and a civic conscience. Science and Engineering Ethics, 19, 1229-1240.

Elections Canada. (2013). Voter turnout at federal elections and referendums. URL: http://www .elections.ca/content.aspx?section=ele\&dir=turn\&document=index\&lang=e .

Freudenburg, W.R., \& Gramling, R. (1994). Bureaucratic slippage and failures of agency vigilance: The case of the environmental studies program. Social Problems, 41(2), 214-239.

Meyer, J.L., Frumhoff, P.C., Hamburg, S.P., \& de la Rosa, C. (2010.) Above the din but in the fray: Environmental scientists as effective advocates. Frontiers in Ecology and Environment, 8(6), 299-305.

MoE. (1991). The federal policy on wetland conservation. Ottawa, ON: Ministry of the Environment, Supply and Services Canada.

Pauley, D., Christensen, V., Dalsgaard, J., Froese, R., \& Torres, F. Jr. (1998). Fishing down marine food webs. Science, 279, 860-863.

Schindler, D.W. (1974). Eutrophication and recovery in experimental lakes: Implications for lake management. Science, 184, 897-899.
Scholarly and Research

Communication

VOlume 5 / ISSUE 1 / 2014 